\title{
Uterine cervix dilatation based on new insights of embryology - method description
}

\author{
Weichselbaum $A^{1,2}$ and Stark $M^{2,3,4 *}$ \\ ${ }^{1}$ NGT Technological Incubator, Nazareth, Israel \\ ${ }^{2}$ New European Surgical Academy, Berlin, Germany \\ ${ }^{3}$ ELSAN Hospital Group, France \\ ${ }^{4}$ Charite University Hospital, Berlin, Germany
}

\section{Introduction}

Intrauterine procedures are one of the most common natural orifices for surgical manipulations. About $20 \%$ of pregnancies end with abortion [1], and since hysteroscopy became an integral part of the gynecological surgeons training [2], its use is increasing worldwide. In USA alone, 7,438,452 women underwent inpatient hysterectomy between 1998 and 2010 [3], many of which require prior intrauterine evaluation.

The curettage process does not require systematically the dilatation of the cervix because in some cases of incomplete abortions, the cervix is already opened. In these cases, curettage can be done without the dilatation of the cervix. However, dilatation is needed for missed abortions, or surgical hysteroscopies. Many of the indications for intrauterine procedures are for diagnostic purposes, but some are for removal of polyps or uterine septum, termination of pregnancies, endometrial sampling, and other indications such as the removal of a lost intrauterine device.

The time-honored method of dilatation is the Hegar's rods which have been used for over 100 years [4]. The advantages of the Hegar's rods are short time needed and the ability to plan in advance the needed dilatation, however, the disadvantage is the risk of cervical incompetence [5]. Possible cervical damage is due to the structure of the cervix. While the body of the uterus consists to up to $68,8 \%$ of muscle tissue, the lower third of the cervix $6.4 \%$ of muscle tissue [6], and the rest is compound of fibrous tissue which becomes expansible only at the onset of delivery due to the hormonal changes. Therefore, a quick dilatation might become traumatic and produce incompetence which affects future pregnancies.

Another traditional way to dilate the cervix is the laminaria. These are taken from the stems of the Algae Laminaria Japonica, are inserted into the cervix where they absorb water and expand in diameter applying radial forces [7]. Dilapan is a modern synthetic version of laminaria [8] which is a cervical dilator made of hydrophilic polymer rod and is also used for induction of labor [9]. The advantages of laminaria are gradual radial dilatation, and therefore the lower risk of cervical incompetence, the relative painlessness, and the stimulation of uterine contractions. However, this method is time-consuming (e.g. 6 hours) to get the optimal dilatation and subsequent infections might rarely occur [10].

For a long time, dilatation and curettage were done in the hospitals, but since the beginning of the 1970s, it gradually became an outpatient

procedure [11]. As the outpatient treatment becomes more frequent, efficient method of user-friendly, quicker dilatation with as little side effects as possible without early and late complications should be looked for.

\section{Materials and methods \\ Description of the device}

The modified cervical dilator (Aqueduct-100) is a triple balloon catheter with a diameter of $2.3 \mathrm{~mm}$ which enables easy insertion into the cervical canal (Figure 1). An anchoring balloon is inflated by using $2.5 \mathrm{ml}$ syringe with $1.5 \mathrm{ml}$ of saline solution in order to fix the catheter in place beyond the internal Os.

Two elongated dilated balloons are inflated simultaneously at each end of the cervical canal by 3 consecutive injections of $2.5 \mathrm{ml}$ saline solution through the "dilation channel". The surgeon controls the inflation rate which is dilated gradually while responding to the resistance created by the cervical walls. The dilating balloons create pressure of up to 6 bars. The time for inflation does not exceed 10 seconds and the inflated balloons stay in cervical canal for up to 7 minutes depending on the desired diameter of the opening (Figure 2). Saline solution can be injected between the two balloons for lubrication.

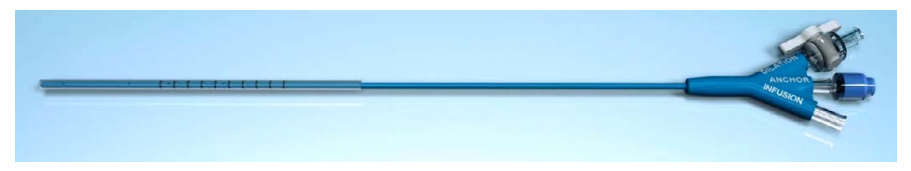

Figure 1. Aqueduct-100, a triple balloon catheter with a diameter of $2.3 \mathrm{~mm}$

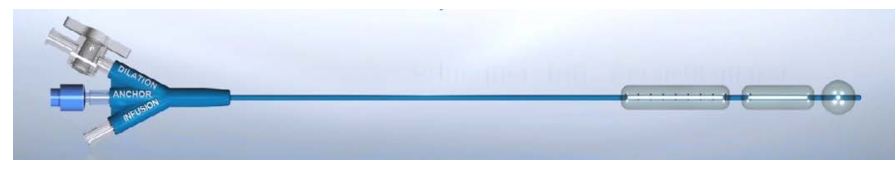

Figure 2. Aqueduct-100 in inflated state

Correspondence to: Michael Stark, New European Surgical Academy, Berlin, Germany, E-mail: mstark@nesacademy.org

Key words: Cervix, Curettage, Hysteroscopy, Laminaria, Hegar

Received: September 04, 2017; Accepted: October 05, 2017; Published: October 09, 2017 


\section{Embryological considerations}

The uterus and the cervix comprise one organ, and embryologically develop together; however, their structure is completely different and should be considered when manipulations in the uterus are performed. In 1830, Johannes Peter Müller described the paramesonephric ducts which are named after him. This time-honored knowledge has never been challenged since [12]. During the pregnancy the uterus expands and during labor it contracts while the cervix is thinning and dilating. In order to achieve it, the histological structure of the uterus and cervix must differ. The amount of smooth muscle in the lower third of the cervix is estimated as $6.4 \%$, in the middle third $18 \%$ and in the upper third $28.8 \%$, but in the body of the uterus it is as high as $68.8 \%$. In addition, the amount of actomyosin in the body of the uterus is significantly higher than in the cervix [13] and was shown to depend on the age and parity of the woman [14]. The cervix does not work as other sphincters in the body and expands passively and gradually. It is a fibrous organ which contains hyaluronic acid, collagen and proteoglycan [15]. The uterus also differs from other muscles of the body, being retractile.

We believe that the different histological structure in each level as defined by the embryology, might have relevance to the way the cervix should be dilated in order to be able to achieve the optimal dilatation which will enable safe and comfortable manipulations inside the uterus without causing long-term complications. The dilatation with Hegar's rods starts at the external Os, and then each part of the cervix is dilated step by step. Doing so, each individual segment of the cervix is stretched in two directions - longitudinal and radial. This might explain the cervical incompetence which might result from this way of dilatation when the fibers are stretched beyond their maximal elastic capacity. The advantage of the Laminaria, beside gradual dilatation of the tissue, is to avoid the longitudinal overstretching. However, it needs two sessions, one for the insertion, and one for the removal. Therefore, a method which enables radial dilatation in a shorter time and dilatation and manipulation at the same session was looked for.

A new device was designed in order to answer these requirements and the following aspects were considered:

1. Cervical dilatation might be technically difficult. Therefore occasionally Misoprostol is used prior to the dilatation [16]. The new device due to its small diameter enables dilatation in ease and steep learning curve.

2. Radial dilatation should be preferred: the new device allows simultaneous radial dilatation of all cervical segments which might reduce the risk of cervical incompetence as the fibers are not torn but are able to stretch passively and gradually.

3. Optimally, short dilatation time should be achieved: it was shown that osmotic dilatation next to Misoprostol were the most effective methods of cervical dilatation but long time is needed [17]. The new device allows to achieve the same results but in a shorter time.

4. Safety: the procedure seems to be safe as it was shown with Dilapan-S [18].

\section{Initial clinical experience and future prospects}

The device which is CE and FDA approved has already been in use in more than 100 patients during ongoing prospective studies in Spain. In this study, in 38 cases the device was left for 5 minutes and the dilatation which was measured before the procedure as $3.0 \mathrm{~mm}( \pm 1.0)$ reached $8.1 \mathrm{~mm}$ [19]. Now, no single complication or adverse event was recorded. The device was used for dilatation before curettage, as well as before diagnostic and surgical hysteroscopy. The device is currently in use at the Mediterranean Hospital in Italy Naples, where over 20 diagnostic and surgical hysterescopies were done and in the Pasteur Hospital in Paris where 19 surgical procedures were successfully done. No single complication was reported or conversion to Hegar's rods was necessary.

\section{Conclusion}

Surgical cervical dilatation contrary to dilatation during labor is non-physiological, might be traumatic and cause damage. Therefore, ways must be found to dilate the cervix with the minimal possible damage, to enable to do it in an outpatient clinic set-up, without usage of general anesthesia and with avoidance of complications.

From the up to date observations, it seems that the Aqueduct- 100 fulfills these requirements. It is user-friendly and enables to dilate the cervix in a couple of minutes in a radial way similar to Laminaria but without the side effects associated with it. There is still no evidence to affirm the assumed advantage concerning cervical incompetence and therefore long-term clinical studies will be needed.

\section{Disclosure}

Amnon Weichselbaum is the inventor of the Aqueduct-100 and the founder of the Aqueduct Medical Ltd.

Michael Stark is the President of New European Surgical Academy and has no personal financial interest.

\section{References}

1. Griebel CP, Halvorsen J, Golemon TB, Day AA (2005) Management of spontaneous abortion. Am Fam Physician 72: 1243-1250. [Crossref]

2. Issat T, Beta J, Januszewski M, Jakimiuk AJ (2017) Cumulative summation test for learning curve (LC-CUSUM) in outpatient hysteroscopy. Ginekol Pol 88: 9-12. [Crossref]

3. Wright JD, Herzog TJ, Tsui J, Ananth CV, Lewin SN, et al. (2013) Nationwide trends in the performance of inpatient hysterectomy in the United States. Obstet Gynecol 122: 233-241. [Crossref]

4. Tschoudowski M (1879) De la dilatation du canal cervical (d'après Hegar). Arch Tocol 6: 737-755

5. Anum EA, Brown HL, Strauss JF 3rd (2010) Health disparities in risk for cervical insufficiency. Hum Reprod 25: 2894-2900. [Crossref]

6. Rorie DK, Newton M (1967) Histologic and chemical studies of the smooth muscle in the human cervix and uterus. Am J Obstet Gynecol 99: 466-469. [Crossref]

7. Abramchenko VV, Gorgidzhanian RS, Novikov EI (1989) [Laminaria in obstetrical and gynecological practice]. Akush Ginekol (Mosk): 12-14. [Crossref]

8. Hern WM (1994) Laminaria versus Dilapan osmotic cervical dilators for outpatien dilation and evacuation abortion: randomized cohort comparison of 1001 patients. $\mathrm{Am}$ J Obstet Gynecol 171: 1324-1328. [Crossref]

9. Newton BW (1971) Laminaria tent: relic of the past or modern medical device? Trans Pac Coast Obstet Gynecol Soc 39: 10-16. [Crossref]

10. Lichtenberg ES (2004) Complications of osmotic dilators. Obstet Gynecol Surv 59: 528-536. [Crossref]

11. Richards MT (1972) Uterine curettage as an office procedure. Can Med Assoc J 107: 133-134. [Crossref]

12. CROSBY WM, HILL EC (1962) Embryology of the Mullerian duct syytem. Review of present-day theory. Obstet Gynecol 20: 507-515. [Crossref]

13. Michael CA (1974) The concentration of actomyosin and soluble protein in uterine muscle. J Obstet Gynaecol Br Commonw 81: 952-955.

14. Huisman CM, Jozwiak M, de Leeuw JW, Mol BW, Bloemenkamp KW (2013) Cervical ripening in the Netherlands: a survey. Obstet Gynecol Int 2013: 745159. [Crossref] 
15. Kavanagh J, Kelly AJ, Thomas J (2006) Hyaluronidase for cervical ripening and induction of labour. Cochrane Database Syst Rev 19: CD003097. [Crossref]

16. Mohammadian S, Tavana A, Tavana S, Mohammadian A, Fallahian M (2015) Cervical Priming by Misoprostol before Diagnostic Dilatation and Curettage: A Randomized Clinical Trial. J Reprod Infertil 16: 162-166. [Crossref]

17. Kapp N, Lohr PA, Ngo TD, Hayes JL (2010) Cervical preparation for first trimester surgical abortion. Cochrane Database Syst Rev CD007207. [Crossref]
18. Lyus R, Lohr PA, Taylor J, Morroni C (2013) Outcomes with same-day cervical preparation with Dilapan-S osmotic dilators and vaginal misoprostol before dilatation and evacuation at 18 to $21+6$ weeks' gestation. Contraception 87: 71-75. [Crossref]

19. Vico de Miguel FJ, Pantoja-Garrido M, Frias-Sanchez Z, Pantoja-Rosso FJ, Martinz E, et al. (2017) Experience with a device for cervical dilatation controlled. Ginecol Obstet Mex 85: 125-133.

Copyright: (C)2017 Weichselbaum A. This is an open-access article distributed under the terms of the Creative Commons Attribution License, which permits unrestricted use, distribution, and reproduction in any medium, provided the original author and source are credited. 